\title{
PREPARO TÉCNICO E PROFISSIONAL EM EAD PARA GESTÃO DE TRÂNSITO: UMA ANÁLISE A PARTIR DE PROGRAMAS APRESENTADOS NA INTERNET
}

Fernanda Antonio Simões | fasimoes@uem.br

Doutorado em Engenharia de Transportes pela Escola de Engenharia de São Carlos, SP. Professora Associada da Universidade Estadual de Maringá, PR.

Eliane Antonio Simões | eliane@uel.br

Doutorado em Engenharia Civil pela Universidade de São Paulo. Coordenadora de cursos de pós-graduação do Instituto de Pesquisas Tecnológicas do Estado de São Paulo (IPT).

Helena Gemignani Peterossi | posgraduacao@centropaulasouza.sp.gov.br Doutorado em Metodologia do Ensino pela Universidade Estadual de Campinas, SP. Professora do Centro Estadual de Educação Tecnológica Paula Souza, SP.

\section{Resumo}

Uma das principais diretrizes para definição de conteúdo programático para cursos técnicos deve ser a formação do profissional em função de sua competência para atuação no mercado de trabalho. Em se tratando da gestão para o trânsito, tem-se carência de profissionais que possam atuar em pequenas e médias cidades brasileiras, com ênfase em estabelecer a mobilidade e a sustentabilidade em áreas urbanas. Para contribuir com essa tarefa, surgem cursos na modalidade a distância que têm suas características apresentadas nas páginas das instituições proponentes. Nesse contexto, o presente trabalho teve por objetivo relacionar o conteúdo programático de interesse para as funções da gestão de trânsito e analisar as propostas de cursos em Educação a Distância $(\mathrm{EaD})$ ofertados no Brasil nessa área. A metodologia foi composta de pesquisa na internet, com coleta de informações sobre o programa, o perfil do aluno e os recursos didáticos utilizados. Os resultados apontaram que os cursos não apresentam conteúdo direcionado para as diversas possibilidades de atuação na área, constituindo-se em multidisciplinares sem foco profissional específico. A maioria dos cursos precisa ajustar o programa à competência profissional para gestão de trânsito, com melhor definição para o perfil do aluno e os recursos didáticos.

\section{Palavras-chave}

Educação a distância. Educação profissional. Formação profissional. Gestão de trânsito. 
Technical and professional preparation in DL for traffic management: an analysis from programs presented on the internet

\section{Abstract}

One of the main guidelines for define content for technical education should be professional in terms of their competence to work in the labor market. When it comes to traffic management has lack of professionals who can work in small and medium-sized Brazilian cities, with an emphasis on establishing the mobility and sustainability in urban areas. To help with this task, there are courses in distance mode, which has its characteristics presented in the web pages of the proposing institutions. In this context, the present study aimed to relate program content relevant to the functions of management traffic and analyze proposals for courses in Distance Learning (DL) offered in this area in Brazil. The methodology consisted of research on the internet, with gathering information about the program, the student's profile and teaching resources used. The results showed that the courses have not targeted content for different possibilities of performance in the field, constituting a multidisciplinary focus without specific professional. Most courses need to adjust the program to professional competence for traffic management, with better definition for the profile of the student and teaching resources.

\section{Keywords}

Distance learning. Professional education. Professional formation. Traffic management.

\section{Introdução}

Em dez anos (de 2000 a 2010), a população brasileira aumentou de 169.799 .170 para 190.732.694 habitantes; também se tornou mais urbanizada, pois nesse período os brasileiros em áreas urbanas passaram de $81 \%$ para $84 \%$ (IBGE, 2010). O número de municípios por classe de população para os anos de 2000 e 2010 está apresentado na Tabela 1; observa-se que a população vem crescendo nos pequenos e médios municípios, pois houve aumento do número de municípios com população entre 10.001 a 500.000 habitantes.

Tabela 1: Número de municípios do Brasil por classe de população - 2000 e 2010.

\begin{tabular}{|c|c|c|c|}
\hline \multirow{2}{*}{ População (habitantes) } & \multicolumn{3}{|c|}{ Número de municípios } \\
\cline { 2 - 4 } & $\mathbf{2 0 0 0}$ & $\mathbf{2 0 1 0}$ & Variação \\
\hline Até 10.000 & 2637 & 2515 & -122 \\
\hline De 10.001 a 50.000 & 2345 & 2443 & +98 \\
\hline De 50.001 a 100.000 & 301 & 324 & +23 \\
\hline De 100.001 a 500.000 & 193 & 245 & +52 \\
\hline De 500.001 a 1.000 .000 & 18 & 23 & +5 \\
\hline De 1.000 .001 a 2.000 .000 & 7 & 9 & +2 \\
\hline De 2.000 .001 a 5.000 .000 & 4 & 4 & - \\
\hline De 5.000 .001 a 10.000 .000 & 1 & 1 & - \\
\hline Mais de 10.000 .000 & 1 & 1 & +58 \\
\hline Brasil - total & 5507 & 5565 & \\
\hline
\end{tabular}

Fonte: IBGE (Censo 2000 e 2010). 
Pode-se observar que, na gestão do trânsito, muitas cidades brasileiras pequenas carecem de setor próprio com profissionais atuantes; as cidades médias, na maioria, têm setor de trânsito, mas em geral não possuem profissionais qualificados. A nova característica esperada para núcleos urbanos é a acessibilidade e mobilidade em transportes, com a exigência de abordagem dos transportes alternativos e da prioridade aos pedestres, o que também deve estar presente nos municípios de pequeno e médio porte para que se proporcione a tão almejada qualidade de vida urbana.

Na Educação, tem-se a preocupação com a formação e a atualização dos profissionais em resposta às demandas da sociedade. Surgem processos facilitadores da comunicação que podem contribuir para o preparo profissional em atendimento ao mercado. Esses processos encontram-se sedimentados em vários países e diversas áreas e, no âmbito geral, caracterizam-se pela Educação a Distância (EaD).

Nos Estados Unidos, no segundo semestre de 2008, houve mais de 4,6 milhões de inscritos em pelo menos um curso on-line, com taxa anual de crescimento igual a $16,9 \%$. Pelo sexto ano consecutivo, o crescimento superou em muito o da educação superior de modo geral (ALLEN; SEAMAN, 2010). Existem muitos cursos de EaD no Brasil que vêm se solidificando e colaborando na inclusão de novos indivíduos no ambiente educacional. Ampliam-se os números $e$ diversidades de cursos, com registro de 2.504.483 alunos em 2008 (ABRAEAD, 2008).

Considerando-se que formas de educação abrangentes que possibilitem o preparo de profissionais para gestão do trânsito nas pequenas e médias cidades brasileiras são necessárias e importantes dentro do cenário nacional, o objetivo do trabalho foi analisar os cursos de Gestão de Trânsito na modalidade EaD, por meio de pesquisa na internet, com coleta de informações sobre o programa, o perfil do aluno e os recursos didáticos utilizados nesses cursos. $\mathrm{O}$ intuito foi verificar a adequação de cursos dessa área na formação profissional e discutir diretrizes para o planejamento de cursos de gestão de trânsito na modalidade EaD.

\section{Metodologia}

Para realização do trabalho foram investigados os conceitos de gestão e trânsito, com reflexões sobre os aspectos programáticos e profissionais envolvidos na gestão do trânsito. Foi feita uma pesquisa exploratória na internet utilizando o site de busca Google. O propósito da busca foi a análise de cursos de Gestão de Trânsito ofertados a distância para profissionais da área. As informações selecionadas nos sites foram sobre o conteúdo programático, o perfil do aluno e os recursos didáticos em $\mathrm{EaD}$ utilizados.

\section{Desenvolvimento}

\subsection{Aspectos conceituais}

A palavra gestão significa gerência, administração, e a palavra trânsito possui os significados de ato ou efeito de caminhar, tráfego, trajeto e movimento de veículos e de pedestres, entre outros (FERREIRA, 2008; DICIO, 2012). Conclui-se, portanto, que a gestão do trânsito diz respeito a gerenciar os trajetos $e$ movimentos, o que configura preparar o sistema viário e organizar os deslocamentos adequadamente para definir o sistema de operação das vias.

A Mobilidade Urbana Sustentável engloba as políticas de transporte e circulação que prioriza as pessoas (não os veículos) e proporciona "o acesso amplo e democrático ao espaço urbano, mediante a priorização dos modos não motorizados e coletivos de transporte, de forma efetiva, que não gere segregações espaciais, socialmente inclusiva e ecologicamente sustentável" (MINISTÉRIO DAS CIDADES, 2004), tendo por diretrizes:

- Priorizar pedestres, ciclistas, passageiros de transporte coletivo, pessoas com deficiência, portadoras de necessidades especiais e idosas;

- Promover a ampla participação cidadã, garantindo o efetivo controle social das políticas de mobilidade urbana; 
- Promover o barateamento das tarifas de transporte coletivo;

- Articular e definir, em conjunto com os estados, Distrito Federal e municípios, fontes alternativas de custeio dos serviços de transporte público, incorporando recursos de beneficiários indiretos no seu financiamento;

- Combater a segregação urbana;

- Promover o acesso das populações de baixa renda, especialmente dos desempregados e trabalhadores informais, aos serviços de transporte coletivo urbano;

- Promover e difundir sistemas de informações e indicadores da mobilidade urbana;

- Estabelecer mecanismos permanentes de financiamento da infraestrutura para os modos coletivos e não motorizados de circulação urbana;

- Incentivar e apoiar sistemas estruturais, metroferroviários e rodoviários de transporte coletivo, em corredores exclusivos nas cidades médias e nas regiões metropolitanas, que contemplem mecanismos de integração intermodal e institucional;

- Promover e apoiar a implementação de sistemas cicloviários seguros, priorizando sua integração à rede de transporte público.

No Brasil, a Lei $\mathrm{n}^{\circ}$ 9.503, de 23 de setembro de 1997, instituiu o Código de Trânsito Brasileiro $\mathrm{CTB}$, que deve ser obedecido para o trânsito no país. $\mathrm{O}$ artigo $1^{\mathrm{O}}$, no Capítulo I, Disposições Preliminares, menciona:

Art. $1^{\circ} \mathrm{O}$ trânsito de qualquer natureza nas vias terrestres do território nacional, abertas à circulação, rege-se por este Código.

$\S 1^{\circ}$ Considera-se trânsito a utilização das vias por pessoas, veículos e animais, isolados ou em grupos, conduzidos ou não, para fins de circulação, parada, estacionamento $e$ operação de carga ou descarga.
$\S 2^{\circ} \mathrm{O}$ trânsito em condições seguras é um direito de todos e dever dos órgãos e entidades componentes do Sistema Nacional de Trânsito, a estes cabendo, no âmbito das respectivas competências, adotar as medidas destinadas a assegurar esse direito.

$\S 3^{\circ}$ Os órgãos e entidades componentes do Sistema Nacional de Trânsito respondem, no âmbito das respectivas competências, objetivamente, por danos causados aos cidadãos em virtude de ação, omissão ou erro na execução $e$ manutenção de programas, projetos e serviços que garantam o exercício do direito do trânsito seguro.

\section{$\S 4^{\circ}$ (VETADO)}

$\S 5^{\circ}$ Os órgãos e entidades de trânsito pertencentes ao Sistema Nacional de Trânsito darão prioridade em suas ações à defesa da vida, nela incluída a preservação da saúde e do meio ambiente (BRASIL, 2008).

O CTB (BRASIL, 2008) indica que o trânsito é dever dos órgãos e entidades componentes do Sistema Nacional de Trânsito, no âmbito das respectivas competências, mas não contém referência aos profissionais que devem responder pela gestão de trânsito. No Capítulo VIII, que trata da Engenharia de Tráfego, tem-se:

Art. 91. O CONTRAN estabelecerá as normas e regulamentos a serem adotados em todo o território nacional quando da implementação das soluções adotadas pela Engenharia de Tráfego, assim como padrões a serem praticados por todos os órgãos e entidades do Sistema Nacional de Trânsito.

Art. 93. Nenhum projeto de edificação que possa transformar-se em polo atrativo de trânsito poderá ser aprovado sem prévia anuência do órgão ou entidade com circunscrição sobre a via e sem que do projeto conste área para estacionamento e indicação das vias de acesso adequadas. (BRASIL, 2008).

O Quadro 1 traz alguns conceitos e definições estabelecidos no Anexo I do CTB (BRASIL, 2008) referentes a itens de trânsito, das vias e da Engenharia. 
Quadro 1: Conceitos e definições estabelecidos no Anexo I do CTB.

\begin{tabular}{|c|c|}
\hline Conceitos & Definições \\
\hline Trânsito & Movimentação e imobilização de veículos, pessoas e animais nas vias terrestres. \\
\hline Calçada & $\begin{array}{l}\text { Parte da via, normalmente segregada e em nível diferente, não destinada à circulação de veículos, reservada ao } \\
\text { trânsito de pedestres e, quando possível, à implantação de mobiliário urbano, sinalização, vegetação e outros fins. }\end{array}$ \\
\hline Pista & $\begin{array}{l}\text { Parte da via normalmente utilizada para a circulação de veículos, identificada por elementos separadores ou por } \\
\text { diferença de nível em relação às calçadas, ilhas ou aos canteiros centrais. }\end{array}$ \\
\hline Via rural & Estradas e rodovias. \\
\hline Via urbana & $\begin{array}{l}\text { Ruas, avenidas, vielas ou caminhos e similares abertos à circulação pública, situados na área urbana, caracteri- } \\
\text { zados principalmente por possuírem imóveis edificados ao longo de sua extensão. }\end{array}$ \\
\hline Ciclovia & Pista própria destinada à circulação de ciclos, separada fisicamente do tráfego comum. \\
\hline Viaduto & Obra de construção civil destinada a transpor uma depressão de terreno ou servir de passagem superior. \\
\hline Estacionamento & Imobilização de veículos por tempo superior ao necessário para embarque ou desembarque de passageiros. \\
\hline Regulamentação da via & $\begin{array}{l}\text { Implantação de sinalização de regulamentação pelo órgão ou entidade competente com circunscrição sobre a } \\
\text { via, definindo, entre outros, sentido de direção, tipo de estacionamento, horários e dias. }\end{array}$ \\
\hline Operação de trânsito & $\begin{array}{l}\text { Monitoramento técnico baseado nos conceitos de Engenharia de Tráfego, das condições de fluidez, de esta- } \\
\text { cionamento e parada na via, de forma a reduzir as interferências tais como veículos quebrados, acidentados, } \\
\text { estacionados irregularmente atrapalhando o trânsito, prestando socorros imediatos e informações aos pedestres } \\
\text { e condutores. }\end{array}$ \\
\hline
\end{tabular}

Fonte: CTB, 2008.

Pode-se dizer que a Engenharia de Tráfego ou de Trânsito contempla as etapas de planejamento, projeto e operação das vias, em conjunto com o meio ambiente viário. Uma das tarefas pertinentes a essa área é a gestão do trânsito, que aborda as estratégias de deslocamento e a operação das vias para um tráfego seguro e eficiente.

Conforme Simões e Simões (2011), os engenheiros civis são os profissionais que estão capacitados a desenvolver o projeto e a execução das vias, assim como o planejamento, o projeto e a operação delas, além da gestão do trânsito, sendo citados os arquitetos urbanistas nos aspectos de desenho das vias, paisagismo e estética no entorno viário, uso e ocupação do solo, entre outras possibilidades. Nesse assunto, a Lei $\mathrm{n}^{\circ} 5.194$, de 24 dezembro de 1966, regula o exercício das profissões de engenheiro, arquiteto e engenheiro agrônomo, e menciona no Capítulo I, Seção I, artigo $1^{\circ}$ que as profissões em questão são caracterizadas pela realização dos empreendimentos: aproveitamento e utilização de recursos naturais; meios de locomoção e comunicações; edificações, serviços e equipamentos urbanos, rurais e regionais, nos seus aspectos técnicos e artísticos; instalações e meios de acesso a costas, cursos e massas de água e extensões terrestres; desenvolvimento industrial e agropecuário (BRASIL, 1966). Na Seção IV, são citadas as atribuições profissionais:

Art. $7^{\circ}$ - As atividades e atribuições profissionais do engenheiro, do arquiteto e do engenheiro agrônomo consistem em:

a) desempenho de cargos, funções e comissões em entidades estatais, paraestatais, autárquicas e de economia mista e privada; 
b) planejamento ou projeto, em geral, de regiões, zonas, cidades, obras, estruturas, transportes, explorações de recursos naturais e desenvolvimento da produção industrial e agropecuária;

c) estudos, projetos, análises, avaliações, vistorias, perícias, pareceres e divulgação técnica;

d) ensino, pesquisa, experimentação e ensaios;

e) fiscalização de obras e serviços técnicos;

f) direção de obras e serviços técnicos;

g) execução de obras e serviços técnicos;

h) produção técnica especializada, industrial ou agropecuária.

$\S$ único - Os engenheiros, arquitetos e engenheiros agrônomos poderão exercer qualquer outra atividade que, por sua natureza, se inclua no âmbito de suas profissões.

Art. $8^{\circ}$ - As atividades e atribuições enunciadas nas alíneas «a», «b», «c», «d», «e» $e$ «f» do artigo anterior são da competência de pessoas físicas, para tanto legalmente habilitadas.

$\S$ único - As pessoas jurídicas e organizações estatais só poderão exercer as atividades discriminadas no Art. $7^{\circ}$, com exceção das contidas na alínea "a», com a participação efetiva e autoria declarada de profissional legalmente habilitado e registrado pelo conselho regional, assegurados os direitos que esta lei lhe confere.

Art. $9^{\circ}$ - As atividades enunciadas nas alíneas «g» $e$ «h» do Art. $7^{\circ}$, observados os preceitos desta lei, poderão ser exercidas, indistintamente, por profissionais ou por pessoas jurídicas.

Art. 10 - Cabe às congregações das escolas e faculdades de Engenharia, Arquitetura e Agronomia indicar ao Conselho Federal, em função dos títulos apreciados através da formação profissional, em termos genéricos, as características dos profissionais por elas diplomados (BRASIL, 1966).
A Resolução $\mathrm{n}^{\circ}$ 1.010, de 22 de agosto de 2005, do Conselho Federal de Engenharia, Arquitetura e Agronomia (Confea), trata da regulamentação da atribuição profissional e tem no Capítulo II, artigo $5^{\circ}$, as atribuições para o desempenho de atividades no âmbito das competências profissionais, dentre elas as seguintes (CONFEA, 2005):

- Gestão, supervisão, coordenação, orientação técnica;

- Coleta de dados, estudo, planejamento, projeto, especificação;

- Estudo de viabilidade técnico-econômica e ambiental;

- Assistência, assessoria, consultoria;

- Direção de obra ou serviço técnico;

- Desempenho de cargo ou função técnica;

- Execução de obra ou serviço técnico;

- Condução de serviço técnico;

- Execução de instalação, montagem, operação, reparo ou manutenção;

- Operação, manutenção de equipamento ou instalação.

No Anexo I da Resolução n 1010 (CONFEA, 2005), as atividades são definidas de forma específica (Quadro 2).

Quadro 2: Algumas definições estabelecidas no Anexo I da Resolução n $1010 / 2005$ - Confea.

\begin{tabular}{|c|c|}
\hline Atividade & Definição \\
\hline Gestão & $\begin{array}{l}\text { Conjunto de atividades que englobam o gerenciamento da concepção, elaboração, projeto, execução, avaliação, implementa- } \\
\text { ção, aperfeiçoamento e manutenção de bens e serviços e de seus processos de obtenção. }\end{array}$ \\
\hline Planejamento & $\begin{array}{l}\text { Atividade que envolve a formulação sistematizada de um conjunto de decisões devidamente integradas, expressas em objetivos } \\
\text { e metas, e que explicita os meios disponíveis ou necessários para alcançá-los, num dado prazo. }\end{array}$ \\
\hline Projeto & $\begin{array}{l}\text { Representação gráfica ou escrita necessária à materialização de uma obra ou instalação, realizada através de princípios técni- } \\
\text { cos e científicos, visando à consecução de um objetivo ou meta, adequando-se aos recursos disponíveis e às alternativas que } \\
\text { conduzem à viabilidade da decisão. }\end{array}$ \\
\hline Execução & $\begin{array}{l}\text { Atividade em que o profissional, por conta própria ou a serviço de terceiros, realiza trabalho técnico ou científico visando à } \\
\text { materialização do que é previsto nos projetos de um serviço ou obra. }\end{array}$ \\
\hline
\end{tabular}




\begin{tabular}{|c|c|}
\hline Avaliação & $\begin{array}{l}\text { Atividade que envolve a determinação técnica do valor qualitativo ou monetário de um bem, de um direito ou de um empre- } \\
\text { endimento. }\end{array}$ \\
\hline Manutenção & Atividade que implica conservar aparelhos, máquinas, equipamentos e instalações em bom estado de conservação e operação. \\
\hline Serviço técnico & Desempenho de atividades técnicas no campo profissional. \\
\hline Trabalho técnico & $\begin{array}{l}\text { Desempenho de atividades técnicas coordenadas, de caráter físico ou intelectual, necessárias à realização de qualquer serviço, } \\
\text { obra, tarefa, ou empreendimento especializados. }\end{array}$ \\
\hline $\begin{array}{l}\text { Orientação } \\
\text { técnica }\end{array}$ & $\begin{array}{l}\text { Atividade de proceder ao acompanhamento do desenvolvimento de uma obra ou serviço, segundo normas específicas, visan- } \\
\text { do a fazer cumprir o respectivo projeto ou planejamento. }\end{array}$ \\
\hline $\begin{array}{c}\text { Desempenho de } \\
\text { cargo ou função } \\
\text { técnica }\end{array}$ & $\begin{array}{l}\text { Atividade exercida de forma continuada, no âmbito da profissão, em decorrência de ato de nomeação, designação ou contrato } \\
\text { de trabalho. }\end{array}$ \\
\hline
\end{tabular}

Fonte: CONFEA, 2005.

Na gestão do trânsito urbano é importante realizar estudos de acessibilidade e mobilidade nos deslocamentos, de segurança viária, de viabilidade de aplicação de transportes alternativos, como os de implantação de redes cicloviárias, sendo fundamental definir os planos de circulação para orientar os usuários do sistema (pedestres e condutores de veículos) nos seus deslocamentos. Entre as atividades constantes nos planos de circulação têm-se as pesquisas de tráfego, a hierarquização viária, a definição de sentidos de circulação e a sinalização viária, incluindo a sinalização semafórica. Na parte de infraestrutura viária, tem-se como fundamental os projetos que envolvem tipo, dimensão e drenagem das vias, além do projeto e da gerência de pavimentos, de acordo com o tipo de via, o solo $e$ as solicitações de carga, indicando a pavimentação adequada $e$ a manutenção $e$ a reabilitação do pavimento, necessárias.

O trânsito tem caráter público; tem-se, então, a gestão pública que reúne a gestão de organizações (com gestão do conhecimento, de pessoas, econômico-financeira, da contabilidade, da tecnologia da informação, logística, de projetos, de processos, de marketing, da produção, de operações, do planejamento estratégico, da comunicação etc.); além disso, o trânsito necessita de planejamento $e$ projetos específicos, sendo considerada a gestão de projetos (envolvendo a gestão de pessoas, tempo, custo, riscos, qualidade, integração, escopo, aquisições, comunicação). Além dessas atividades, a gestão do trânsito deve englobar conhecimentos técnicos de engenharia de tráfego no que concerne ao planejamento, projeto e operação do sistema viário e de trânsito.

Para capacitar ao exercício profissional, têm-se os processos educacionais, fornecendo atribuições de acordo com as competências e programas de cursos de graduação em relação a uma profissão. Também os cursos de especialização (lato sensu) podem contribuir nas atualizações e/ou complementações de conteúdos inerentes à profissão de exercício.

Dentre os processos educacionais há os que acontecem na modalidade a distância. O Decreto 
$\mathrm{n}^{\circ} 5.622$, de 19 de dezembro de 2005 (que regulamenta o artigo 80 da Lei $n^{\circ} 9.394$, de Diretrizes e Bases da Educação Nacional), no seu artigo $1^{\circ}$, caracteriza a Educação a Distância como:

modalidade educacional na qual a mediação didático-pedagógica nos processos de ensino e aprendizagem ocorre com a utilização de meios e tecnologias de informação e comunicação, com estudantes e professores desenvolvendo atividades educativas em lugares ou tempos diversos (BRASIL, 2005).

Ainda no parágrafo segundo do Artigo $1^{\circ}$ tem-se que a Educação a Distância poderá ser ofertada nos seguintes níveis e modalidades educacionais: educação básica; educação de jovens e adultos; educação especial, respeitadas as especificidades legais pertinentes; educação profissional: técnicos de nível médio, e tecnológicos de nível superior; educação superior nos cursos e programas sequenciais, de graduação, de especialização, de mestrado e de doutorado (BRASIL, 2005).

Conforme Moore e Kearsley (2008, p. 2), Educação a Distância é o

aprendizado planejado que ocorre normalmente em um lugar diferente do local do ensino, exigindo técnicas especiais de criação do curso e de instrução, comunicação por meio de várias tecnologias e disposições organizacionais e administrativas especiais.

A Educação a Distância proporciona um acesso mais fácil e melhores recursos de aprendizado, ampliando as possibilidades para além daquelas disponíveis localmente.

À medida que a utilização da educação a distância se disseminar, populações anteriormente em desvantagem, como os alunos de áreas rurais ou de regiões no interior das cidades, poderão fazer cursos nas mesmas instituições e com o mesmo corpo docente que anteriormente estavam disponíveis apenas para alunos em áreas privilegiadas $e$ residenciais de bom nível.
Adultos que precisarem de treinamento especializado para melhorar seu desempenho profissional ou obter aptidões básicas poderão fazer cursos sem ter de se afastar de casa ou do trabalho (MOORE; KEARSLEY, 2008, p. 21).

Portanto, a EaD é uma modalidade que pode contribuir para educação, formação ou atualização de profissionais em diversos pontos distintos de um território e com o mesmo interesse de atuação.

Para Chaney et al (2010), os cursos em EaD têm que ser desenvolvidos com projetos específicos, com maior preocupação com o processo educacional, elaborados a partir das necessidades dos atores envolvidos, com seleção de recursos tecnológicos adequados; a instituição proponente tem que fornecer o apoio necessário. Os autores apresentam cinco pressupostos para o sucesso de cursos realizados a distância (CHANEY et al, 2010):

- Ensino a distância não é superior ou inferior ao ensino presencial tradicional;

- Programas de aprendizagem a distância são movidos por ensinar e aprender, muito além da tecnologia;

- Princípios de gestão de marketing se aplicam a programas de aprendizagem a distância (a comercialização de cursos a distância progride por meio de conceitos de produto, vendas e cliente);

- Cursos e programas a distância têm que atender a necessidades de múltiplos componentes (alunos, professores, departamentos, profissões, administradores etc.);

- Tem que haver uma cultura de suporte em todos os níveis da instituição.

Os autores concluem que a aprendizagem a distância requer uma quantidade significativa de apoio organizacional, avaliação de necessidades das partes interessadas, planejamento estratégico, implementação e avaliação. Eles citam um relatório sobre avaliação de aprendizado on-line (CHANEY et al, 2010) em que há informações de que 
alunos com instrução on-line têm, em média, desempenho melhor que alunos com instrução presencial e que instruções combinadas (on-line e presencial) são mais vantajosas (U.S. DEPARTMENT OF EDUCATION, 2010).

\subsection{Cursos de Gestão de Trânsito em EaD}

Foram encontrados cinco cursos em Gestão de Trânsito na modalidade a distância - quatro de pósgraduação lato sensu e um curso aberto de capacitação profissional (Quadro 3).

Quadro 3: Cursos de Gestão de Trânsito na modalidade a distância

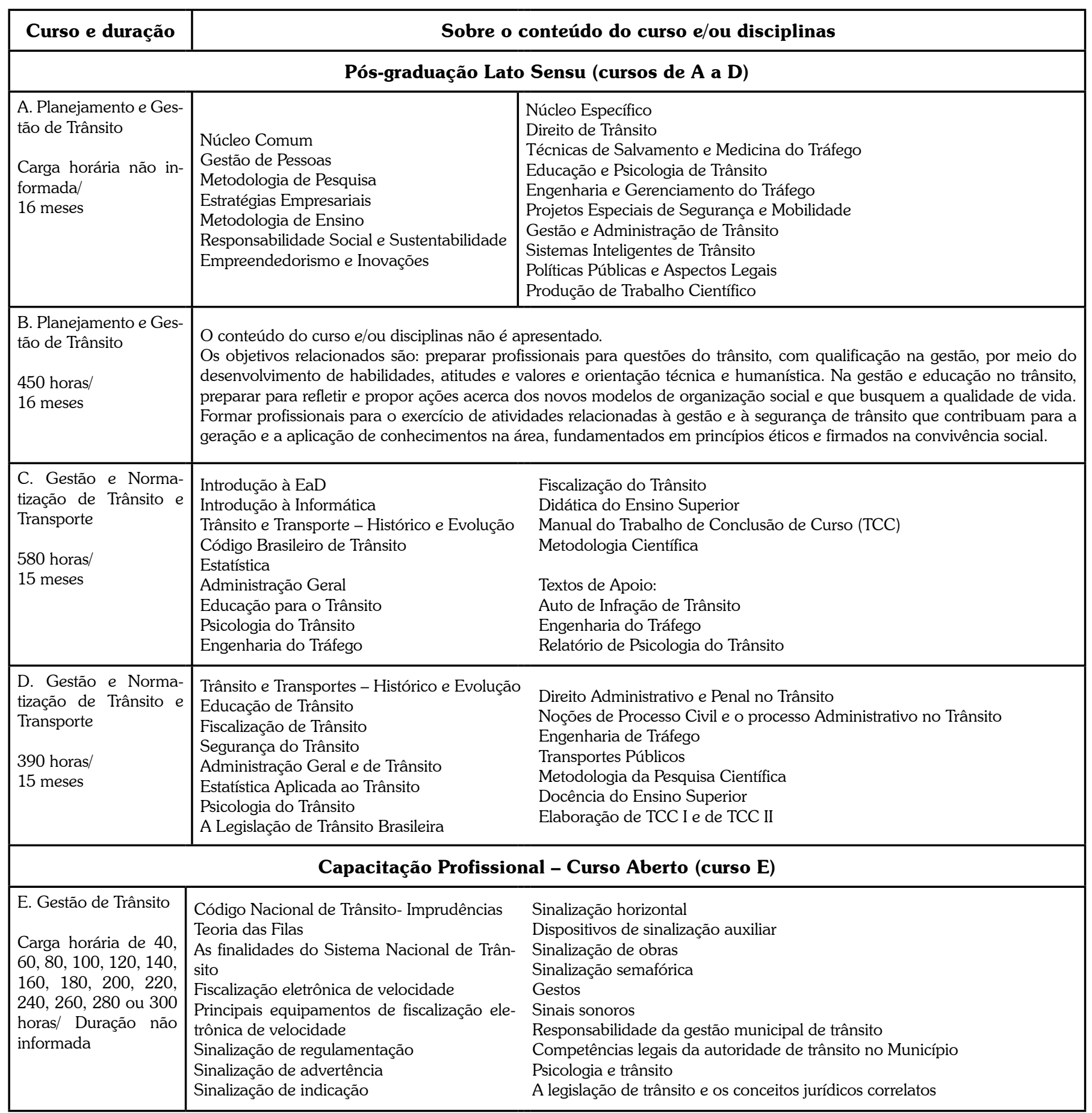

Fonte: CESUMAR (2012); INSPIRAR/UNIUBE (2012); IBE Virtual (2012); ENSINO NACIONAL (2012). 
Pode-se notar que a maioria dos cursos de pósgraduação lato sensu em Gestão de Trânsito tem conteúdo bastante amplo, abrangendo várias áreas. Cabe observar que, na maioria dos cursos pesquisados, as disciplinas isoladas apresentam mesma carga horária. Dentro de um tema multidisciplinar é interessante o conhecimento de outras áreas, mas o conteúdo deve ser apresentado com maior ênfase para a atuação profissional específica, o que não fica claro na oferta dos cursos.

Na especialidade, para a gestão do trânsito, temse como primordial o planejamento, a infraestrutura e a operação segura do sistema viário para todos os modais e todos os usuários (pessoas, condutores, veículos, passageiros e cargas). Existem outras gerências ligadas ao trânsito que poderiam ser denominadas gestão da educação para o trânsito, gestão das políticas públicas para o trânsito; gestão da orientação e fiscalização do trânsito; gestão da saúde no trânsito; gestão de atendimentos emergenciais; dentre algumas possibilidades. Os cursos pesquisados apresentam alguns conteúdos generalistas de gestão, mas ainda carecem de alguns, e apresentam especificidades das profissões dos diversos setores sem foco definido para uma delas.

Os cursos vêm sendo propostos igualmente para contribuir com a segurança no trânsito, tendo em vista que os índices de acidentes são elevados e inaceitáveis para a sociedade como um todo. Eles são importantes nesse aspecto e na multidisciplinaridade, não sendo apenas de gestão do trânsito, e sim abordam o trânsito em ambiente multidisciplinar.

Quanto ao perfil do aluno, conforme o Quadro 4 , os cursos permitem a inscrição de muitos profissionais que atuam de forma distinta.

Quadro 4: Perfil dos alunos nos cursos de Gestão de Trânsito pesquisados

\begin{tabular}{|c|l|}
\hline Curso & \multicolumn{1}{|c|}{ Perfil do aluno } \\
\hline A & $\begin{array}{l}\text { Profissionais com formação superior que pretendam atuar ou que atuem em atividades no setor de trânsito, em soluções de trânsito e } \\
\text { mobilidade urbana. }\end{array}$ \\
\hline B & $\begin{array}{l}\text { Profissionais com formação superior que pretendam atuar ou que atuem em atividades no setor de trânsito, em soluções de trânsito e } \\
\text { mobilidade urbana. }\end{array}$ \\
\hline C & Não informado. \\
\hline D & $\begin{array}{l}\text { Funcionários de prefeituras, empresas de trânsito e transporte, Centros de Formação de Condutores (CFCs), policiais militares, rodoviários } \\
\text { e demais profissionais com curso superior. }\end{array}$ \\
\hline E & Ensino médio (não obrigatório). \\
\hline
\end{tabular}

Fonte: CESUMAR (2012); INSPIRAR/UNIUBE (2012); IBE Virtual (2012); ENSINO NACIONAL (2012).

Os cursos acabam por não contribuir para a verdadeira atuação profissional em Gerência de Trânsito, confundindo o que seria essa tarefa, pois as turmas dos cursos de pós-graduação lato sensu de Gestão de Trânsito podem ser compostas de profissionais como engenheiros, educadores, policiais, advogados, psicólogos, administradores, entre outros com curso superior. Alguns realizam o curso para obtenção do certificado e promoção na carreira, o que é válido, mas seria mais proveitoso um curso direcionado às suas ativida- des. O curso aberto (curso E) em gestão de trânsito apresenta como requisito de entrada o ensino médio não obrigatório, o que não apresenta clareza.

Os recursos didáticos referentes aos cursos analisados estão no Quadro 5. Em síntese, foram observados para a modalidade à distância: ambiente virtual de aprendizagem; material didático on-line; aulas virtuais; aulas acompanhadas em polo de apoio ou pela internet; fóruns; comunicação via email; avaliações de aprendizagem presenciais e a distância. 
Quadro 5: Recursos didáticos nos cursos de Gestão de Trânsito pesquisados

\begin{tabular}{|c|l|}
\hline Curso & \multicolumn{1}{c|}{ Recursos didáticos } \\
\hline A & $\begin{array}{l}\text { Ambiente virtual de aprendizagem: material didático impresso ou on-line e materiais extras, disponíveis em formato eletrônico; aulas virtu- } \\
\text { ais produzidas e gravadas ou aulas ao vivo (gravadas e armazenadas no ambiente virtual) que podem ser vistas no polo de apoio presencial } \\
\text { ou pela internet; fóruns com participações avaliadas; atividades on-line de estudo individual, questionários disponibilizados no ambiente } \\
\text { virtual; atividades dissertativas interdisciplinares postadas no ambiente virtual; provas presenciais e trabalho de conclusão de curso. }\end{array}$ \\
\hline B & Aulas ao vivo com apoio do polo mais próximo ou via internet. \\
\hline C & $\begin{array}{l}\text { Material didático em apostilas com avaliação presencial; encontros presenciais para realização das avaliações e para orientação e entrega } \\
\text { do trabalho final; dúvidas respondidas via email. }\end{array}$ \\
\hline D & $\begin{array}{l}\text { Material didático em apostilas com avaliação presencial; encontros presenciais para realização das avaliações e para orientação e entrega } \\
\text { do trabalho final; dúvidas respondidas via email. }\end{array}$ \\
\hline E & $\begin{array}{l}\text { Material apresentado por apostila, vídeo, áudio, imagem, animação em flash, software, referência, texto/HTML, com observação de que os } \\
\text { cursos podem não apresentar todas as mídias. }\end{array}$ \\
\hline
\end{tabular}

Fonte: CESUMAR (2012); INSPIRAR/UNIUBE (2012); IBE Virtual (2012); ENSINO NACIONAL (2012).

O curso A de Gestão de Trânsito é o que apresenta melhores recursos para o desenvolvimento em EaD, mencionando o ambiente virtual de aprendizagem (AVA), que é uma ferramenta de comunicação ampla, que possibilita a adoção de atividades de troca de informações on-line, como os fóruns. Os outros cursos não citam o AVA; os cursos B, C e D são precários em termos de recursos didáticos, com dúvidas respondidas por e-mail. O curso $\mathbf{E}$ contém uma ressalva de que os cursos podem não apresentar todas as mídias relacionadas na sua página da internet.

\section{Conclusão}

Os cursos de Gestão de Trânsito são essenciais ao preparo de profissionais para promoção de cidades mais sustentáveis e com maior mobilidade. As perspectivas devem contemplar as atividades de um gerente ou administrador do sistema viário, ou seja, formar um profissional apto a responder às questões de gerenciamento dos deslocamentos, o que deveria conter generalidades sobre gestão pública e especificidades sobre a gerência de vias com os planos urbanos para rede viária, os projeto de vias e a circulação, a operação do tráfego, a gerência de pavimentos, os estudos especiais de segurança e mobilidade, dentre outras matérias. Os cursos que foram analisados não têm conteúdo direcionado para as diversas possibilidades de atuação na área, constituindo-se em multidisciplinares sem foco profissional específico.

O perfil dos alunos é muito diversificado nesses cursos, e, de certa maneira, o que se apresenta é que a palavra gestão pode, sem critério, reunir todos os tipos de profissionais que atuam na área de trânsito.

Os recursos de EaD utilizados na maioria dos cursos são precários, pois não mencionam AVAs e têm dúvidas esclarecidas por e-mail, o que não contribui muito para o sistema de ensino-aprendizagem a distância. Além disso, o caráter das aulas pouco se altera em relação à modalidade presencial, quando são realizadas aulas transmitidas ao vivo para polos de ensino.

Conclui-se, portanto, que os cursos precisam ajustar o programa à competência profissional para gestão de trânsito, com melhor definição para o perfil do aluno, e que os recursos didáticos em EaD devem ser melhorados para a maioria deles.

Nas propostas de novos cursos devem ser consideradas as necessidades de conteúdo e formação para os profissionais de gestão do trânsito. Pesquisas com esses profissionais poderiam contribuir nessa tarefa. Assim, a formação seria mais direcionada e adequada ao exercício complexo de promover um trânsito seguro e sustentável. 


\section{Referências}

ABRAEAD. Anuário Brasileiro Estatístico de Educação Aberta e a Distância. Coordenação de Fábio Sanchez. Vários colaboradores. Apoio ABED - Associação Brasileira de Educação a Distância. $4^{a}$ ed. São Paulo: Instituto Monitor, 2008.

ALLEN, I. E.; SEAMAN, J. Learning on demand: online education in the United States, 2009. EUA, 2010. Disponível em: <http://www.sloanconsortium.org/publications/survey/pdf/learningondemand.pdf > . Acesso em: 27 nov. 2012.

ALLEN, I. E.; SEAMAN J. Going the distance online education in the United States. EUA, Babson Survey Research Group and Quahog Research Group, LLC, 2011.

BRASIL. Lei no 5.194, de 24 dezembro de 1966. Brasília. Presidência da República, 1966.

Decreto no 5.622, de 19 de dezembro de 2005. Brasília. Presidência da República, 2005.

Código de Trânsito Brasileiro: instituído pela Lei $n^{\circ}$ 9.503, de 23 de setembro de 1997. $3^{a}$ ed. Brasília: Denatran, 2008.

CHANEY, D.; CHANEY, E.; EDDY, J. The context of distance learning programs in higher education: five enabling assumptions. Online Journal of Distance Learning Administration, v. XIII, n. IV. EUA. University of West Georgia, Distance Education Center, Winter 2010.

CONFEA - Conselho Federal de Engenharia, Arquitetura e Agronomia. Resolução no 1.010 , de 22 de agosto de 2005. Brasília. Confea/Crea.

DICIO. Dicionário Online de Português. Vários autores e fontes de referência. Empresa 7Graus. 2012. Disponível em:<http://www.dicio.com.br>. Acesso em: 28 nov. 2012.

FERREIRA, A. B. H. Míni Aurélio - o dicionário da língua portuguesa. 7ª ed. Curitiba: Positivo, 2008.

IBGE. INSTITUTO BRASILEIRO DE GEOGRAFIA E ESTATÍSTICA. Censo 2000. Brasília, Ministério do Planejamento, Orçamento e Gestão, 2000.

. Censo 2010. Brasília, Ministério do Planejamento, Orçamento e Gestão, 2010.

MEC/INEP/DEAES. A trajetória dos cursos de graduação a distância. Dados coletados por Dilvo Ristoff (DEAES). Brasília: Ministério da Educação, 2012.

MINISTÉRIO DAS CIDADES. Política Nacional de Mobilidade Urbana Sustentável. Cadernos MCidadesMobilidade Urbana. Brasília: Ministério das Cidades, 2004.

MOORE, M. G.; KEARSLEY, G. Educação a distância: uma visão integrada. Tradução Roberto Galman, São Paulo, Cengage Learning, 2008.

SIMÕES, F; SIMÕES, E. Série de Cadernos Técnicos da Agenda Parlamentar do Crea-PR - Sistema Viário e Trânsito Urbano. Curitiba: Crea/PR, 2011. Disponível em: <http://www.crea-pr.org.br/index.php?option=com_ phocadownload\&view=category\&id=37:cadernos-tecnicos $>$. Acesso em: 23 jun. 2012.

U. S. DEPARTMENT OF EDUCATION. Office of Planning, Evaluation, and Policy Development and Program Studies Service. Evaluation of evidence-based practices in online learning: a meta-analysis and review of online learning studies. EUA. Washington, D.C., 2010. Disponível em: <http://www2.ed.gov/ rschstat/eval/tech/evidence-based-practices/finalreport.pdf> . Acesso em: 28 nov. 2012. 